\title{
Potential Applications of Microparticulate-Based Bacterial Outer Membrane Vesicles (OMVs) Vaccine Platform for Sexually Transmitted Diseases (STDs): Gonorrhea, Chlamydia, and Syphilis
}

\author{
Christiane Chbib ${ }^{1}$, Sarthak M. Shah ${ }^{2}$, Rikhav P. Gala ${ }^{3}$ and Mohammad N. Uddin ${ }^{2, *}$ \\ 1 Department of Pharmaceutical Science, College of Pharmacy, Larkin University, Miami, FL 33169, USA; \\ cchbib@ularkin.org \\ 2 Department of Pharmaceutical Sciences, College of Pharmacy, Mercer University, Atlanta, GA 30341, USA; \\ sarthak.modi.shah@live.mercer.edu \\ 3 Fraunhofer USA, Center Mid-Atlantic, Biotechnology Division, Newark, DE 19702, USA; \\ Rgala@fraunhofer.org \\ * Correspondence: uddin_mn@mercer.edu; Tel.: +1-678-547-6224
}

\section{check for} updates

Citation: Chbib, C.; Shah, S.M.; Gala, R.P.; Uddin, M.N. Potential Applications of

Microparticulate-Based Bacterial Outer Membrane Vesicles (OMVs) Vaccine Platform for Sexually Transmitted Diseases (STDs): Gonorrhea, Chlamydia, and Syphilis. Vaccines 2021, 9, 1245. https:// doi.org/10.3390/vaccines9111245

Academic Editor: François Meurens

Received: 18 September 2021

Accepted: 25 October 2021

Published: 27 October 2021

Publisher's Note: MDPI stays neutral with regard to jurisdictional claims in published maps and institutional affiliations.

Copyright: (c) 2021 by the authors. Licensee MDPI, Basel, Switzerland. This article is an open access article distributed under the terms and conditions of the Creative Commons Attribution (CC BY) license (https:// creativecommons.org/licenses/by/ $4.0 /)$.
Abstract: Sexually transmitted diseases (STDs) are a major global health issue. Approximately 250 million new cases of STDs occur each year globally. Currently, only three STDs (human papillomavirus (HPV), hepatitis A, and hepatitis B) are preventable by vaccines. Vaccines for other STDs, including gonorrhea, chlamydia, and syphilis, await successful development. Currently, all of these STDs are treated with antibiotics. However, the efficacy of antibiotics is facing growing challenge due to the emergence of bacterial resistance. Therefore, alternative therapeutic approaches, including the development of vaccines against these STDs, should be explored to tackle this important global public health issue. Mass vaccination could be more efficient in reducing the spread of these highly contagious diseases. Bacterial outer membrane vesicle (OMV) is a potential antigen used to prevent STDs. OMVs are released spontaneously during growth by many Gram-negative bacteria. They present a wide range of surface antigens in native conformation that possess interesting properties such as immunogenicity, adjuvant potential, and the ability to be taken up by immune cells, all of which make them an attractive target for application as vaccines against pathogenic bacteria. The major challenge associated with the use of OMVs is its fragile structure and stability. However, a particulate form of the vaccine could be a suitable delivery system that can protect the antigen from degradation by a harsh acidic or enzymatic environment. The particulate form of the vaccine can also act as an adjuvant by itself. This review will highlight some practical methods for formulating microparticulate OMV-based vaccines for STDs.

Keywords: antibiotic; chlamydia; gonorrhea; syphilis; sexually transmitted diseases (STDs); microparticulate; vaccine; outer membrane vesicles (OMV)

\section{Introduction}

According to the Center of Disease Control (CDC), several STDs that are still of concern to public health and safety include bacterial vaginosis, chlamydia, gonorrhea, viral hepatitis, genital herpes, HIV / AIDS, HPV, pelvic inflammatory disease (PID), syphilis, trichomoniasis, chancroid, and scabies [1]. Most STDs are caused by Gram-negative bacterial infection and transmission, specifically, gonorrhea, chlamydia, and syphilis [1-3]. STDs are highly contagious and are passed along to other individuals via vaginal, oral, or anal sex [1].

In this review, we aim to summarize the recent advances on OMVs as vaccine candidates against STDs, with special emphasis on Chlamydiae trachomatis, Treponema pallidum, and Neisseria gonorrhoeae. 
Chlamydia is considered one of the most common STDs in both men and women. In a recent study conducted by CDC, many cases of chlamydia in the United States were reported between 2015 and 2019. During this period, a significant increase in chlamydia infections was observed from 2015 (1,526,658 cases) to 2019 (1,808,703 cases) [4]. Chlamydia is a common STD caused by Chlamydia trachomatis [5]. Women infected may experience pain during intercourse, a burning sensation when urinating, and abnormal vaginal discharge. Men may experience symptoms such as a burning sensation when urinating, itching or burning around the opening of the penis, and pain and swelling of the testicles $[5,6]$. Chlamydia is currently treated with antibiotics; however, this approach appears to be less effective in reducing the prevalence of this infection. Therefore, the development of a vaccine might hold promise in preventing this disease, resulting in a reduced number of cases.

Syphilis is another commonly occurring STD caused by the spirochete bacterium Treponema pallidum. In 2019, 129,813 cases of syphilis were reported in the United States. This number is less compared to 616,392 cases of gonorrhea reported that year, but is significantly higher than 37,968 new diagnoses of HIV infection [7] that year. The CDC reported that the number of individuals diagnosed with syphilis is increasing. Congenital syphilis, where the bacterium is passed from pregnant women to their babies, continues to be a public health concern. In 2019, approximately 1900 new cases of congenital syphilis were reported [8]. Syphilis is transmitted between individual by direct contact during anal, vaginal, or oral sex, specifically when an individual comes in direct contact with a syphilitic sore known as a chancre. This disease is highly contagious, and because its transmission occurs by contact with primary chancres or via secondary lesions, prevention of this disease would be the most effective way to reduce the number of cases. In this scenario, successful development of a vaccine could be the most effective way for controlling this disease $[8,9]$.

Gonorrhea, which is also a common STD, is caused by Gram-negative diplococcus bacteria, Neisseria gonorrhoeae. In 2019, a total of 616,392 cases of gonorrhea were reported to the CDC. This was the second-most common notifiable conditions in the United States for that year, with an uprise of a staggering $92.0 \%$ since their historic low in 2009. During 2018-2019, the overall rate of reported gonorrhea increased 5.7\%. Rates of reported cases increased across different regions, gender, race, and ethnicity. Since 2013, the rate of gonorrhea infection has been found to be higher in men compared to women. Among men, the rate of reported gonorrhea increased 5.9\% during 2018-2019 and 60.6\% during 2015-2019. Rates among women increased 5.1\% during 2018-2019 and 43.6\% during 2015-2019 [7]. Currently, gonorrhea is treated and cured with antibiotic therapy, but the emergence of multi-drug resistant gonorrhea poses an important challenge for future treatment options. A vaccine could be a more effective way to prevent the disease and reduce its number of cases.

As discussed before, the current treatment for gonorrhea, chlamydia, and syphilis are solely dependent on antibiotic therapy. However, there is a growing concern about the future of antibiotic therapy for these diseases due to the emergence of bacterial resistance to one or multiple classes of antibiotics. This may leave us with a few or no options for effective antibiotic therapy for those diseases. To reduce the incidence of resistance organisms, the CDC updated its guidelines to increase the dose of these drugs. In 2010, they provided guidelines for the treatment of uncomplicated gonococcal infections of the urethra, rectum, and cervix by a one $250 \mathrm{mg}$ intramuscular (IM) dose of ceftriaxone and one $1 \mathrm{~g}$ oral dose of azithromycin [10]. However, the guidelines for treating gonococcal infections changed ten years later in 2020, by increasing the ceftriaxone (IM) dose from $250 \mathrm{mg}$ to $500 \mathrm{mg}$. The CDC acknowledged that the effectiveness of this treatment regime may dwindle due to the increase in gonorrhea's ability to acquire antimicrobial resistance at an alarming rate [10]. The rise in resistance indicates that the treatment guidelines may change again in the future to combat STDs effectively. Another possible way to treat these STDs can be accomplished by formulating a microparticulate-based bacterial outer membrane vesicle (OMV) vaccine. This review discusses the structure and composition of 
OMVs, the potential of OMVs as vaccine platforms, and highlight some practical methods for formulating a particulate vaccine for the prevention or treatment of STDs.

\section{Structure, Function, and Composition of OMVs}

OMVs are spherical vesicles with a size of $20-250 \mathrm{~nm}$ produced naturally by Gramnegative bacteria. The vesicles are formed by lipid bilayer membranes derived from the bacterial outer membrane [11-13]. OMV consists of a wide variety of bacterial-derived products such as enzymes, antigens, virulence factors, and pathogen-associated molecular patterns (PAMPs) such as lipopolysaccharides, DNA, RNA, peptidoglycans, and others [14]. Bacteria may produce OMVs, bringing about favorable changes within their environment that promote their growth and survival $[15,16]$. Research shows that OMVs could contain virulence factors and modulate the host immune system during pathogenesis while helping them with nutrient acquisition, ecological niche safeguarding $[17,18]$, and providing structural support through biofilm formation $[19,20]$.

The cell envelope of Gram-negative bacteria (Figure 1) is the primary source of OMVs. It consists of two membranes: the outer membrane and the cytoplasmic membrane. The space between each membrane is known as periplasmic space, consisting of a layer of peptidoglycan (PG) with periplasmic proteins [15]. The outer membrane is usually formed of phospholipids and lipopolysaccharides (LPS), also known as endotoxins. The cytoplasmic membrane comprises a phospholipid bilayer, which acts as an electrochemical barrier [15]. LPS is composed of a lipid, a core made of oligosaccharides, and an antigen.

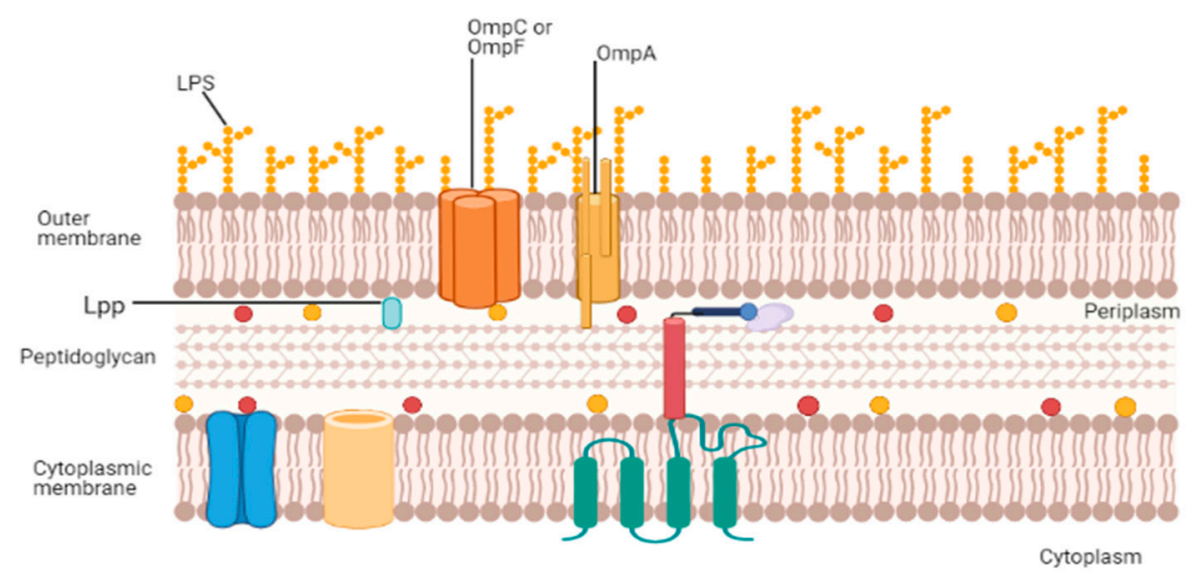

Figure 1. Composition of Gram-negative cell envelope [12]. LPS: lipopolysaccharides, Lpp: Braun's lipoprotein, and OmpC/F/A: outer-membrane protein.

OMVs are spherical portions ( $20-250 \mathrm{~nm}$ in diameter) of the outer membrane, comprising periplasmic luminal elements with the ability to bud and detach from the cell during active growth [16]. Therefore, the biogenesis of OMVs depends on the dissociation of the outer membrane from the underlying PG in areas, followed by a split without affecting the envelope integrity (Figure 2) [16-20].

Multiple factors influence the biogenesis of the OMVs in bacteria. OMV production is enhanced in areas with reduced Braun's lipoprotein (Lpp) and prostaglandin crosslinks. In places where misfolded proteins accumulate, crosslinks can be relocated or depleted, leading to outer membrane bulging, increasing OMV production [12]. OMVs play essential roles in bacterial physiology. While stress conditions enhance OMV production, an OMV removes toxic compounds responsible for creating stress. OMVs are also a good source of carbon and nitrogen and provide the bacterial cell with essential nutrients by breaking down macromolecules. Additionally, OMVs hold iron and zinc acquisition systems that allow bacteria to extract these essential metals for survival [12]. OMVs play essential roles in biofilm formation, regulating bacterial virulence and drug resistance [22,23]. 


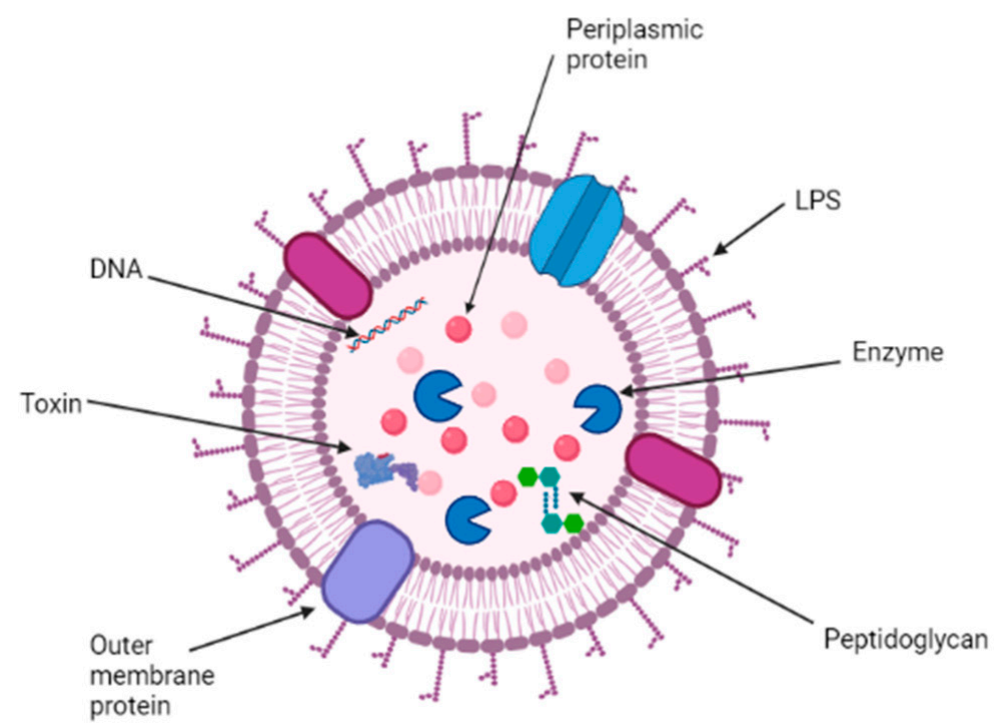

Figure 2. Structure and content of Gram-negative bacterial outer membrane vesicle (OMV) [21].

\section{Isolation of OMVs}

OMVs are naturally produced from the bacterial cell surface. They are concentrated in the cell-free supernatant of bacterial cultures. To isolate OMVs, different methods can be applied to purify crude OMVs. Analysis methods include protein profiling, detection of indicator proteins (immunoblot analysis), lipid profiling (lipid extraction and LC-MS analysis), vesicle size determination, a rough estimation of biomass, and quantifications of defined OMV components [24-28].

OMVs that are obtained for vaccine formulations are of different types. The first type is spontaneous "sOMVs", which are produced naturally from the budding of bacteria. The second type of OMVs is detergent "dOMVs", produced after a selected detergent is applied to the bacterium. The third type is native "nOMVs", which are produced using nondetergent methods such as sonication. Immunologically, OMVs produced from the bacterium via a detergent intervention are different from OMVs made from sOMVs and nOMVs [29].

\section{OMVs as a Vaccine Candidate}

OMVs as a vaccine tool have been researched for many years [30]. Recently, the use of OMVs against Neisseria meningitidis was assessed [31]. It was shown that the complex formed from the adjuvant lipopolysaccharide (LPS) and bacterial surface antigen allows OMVs to generate an adaptive immune response (Figure 2). This result raises the possibility that the OMVs could be used as a vaccine if we can overcome its inherent limitation of instability.

OMVs, which are spontaneously released by many Gram-negative bacteria, possess immunogenicity, adjuvant potential, and the ability to be taken up by immune cells. These features make them an attractive target for application as vaccines against pathogenic bacteria. By definition, a vaccine is a pharmaceutical product that stimulates the immune system to prevent pathogens from causing disease. To elicit an immune response specific for a pathogen, a vaccine product should resemble a pathogen without causing any disease associated with an antigen [32]. From a vaccine development standpoint, a vaccine candidate ideally should have a size similar to that of the natural antigen. The vaccine candidate should also contain a pathogen-associated molecular pattern. In contrast, there are several unwanted properties that a vaccine candidate should not possess. Examples of such unwanted properties include creating an enormous variety of specific surface components, mimicry with host components, production of proteases that degrade antibodies, or development of biofilms. These are not desired in a vaccine candidate, as they can cause the pathogens to develop various immune evasion strategies. 
Considering the availability of desirable features, OMVs are incorporated in vaccine formulations. OMVs have a proper size (20-200 $\mathrm{nm})$ to enable their entry into lymphatic vessels and subsequent uptake by antigen-presenting cells [8]. This size resembles the size of a virus with a range of 20 to $300 \mathrm{~nm}$ [12]. Due to the size of OMVs, they are identified as foreign matter in the body and trigger an immune response. This size similarity enables OMVs to enter lymphatic vessels and be taken up by antigen-presenting cells [33]. OMVs also contain natural components that stimulate humoral and cell-mediated immune responses, since they resemble the bacterial antigenic surface of the pathogen [34]. One potential advantage of their use in vaccine formulations is that because OMVs do not have a series of other host proteins, chances for potential side effects are avoided [34].

Recent studies have reported specific characteristics of OMVs in different Gramnegative bacteria. The OMV of Chlamydia trachomatis is consistent with the general structure in Figure 2. Recent studies have shown that HtrA, a highly conserved protein, is released in the cytoplasm of chlamydial-infected cells. It has been shown to play a major role in the infection pathology [35]. Chlamydia has an outer membrane that contains the typical lipopolysaccharide and proteins but lacks peptidoglycan layer, which makes it different from other Gram-negative bacteria [36].

The peptidoglycan layer of Treponema pallidum is chemically different, thinner, and further distal from the outer membrane when compared to the typical Gram-negative bacteria in Figure 2. It does contain a minor amount of lipoprotein but lacks lipopolysaccharides [37] in addition to the structural feature of Tp0624, which prevents it from binding to typical peptidoglycan [38]. On the other hand, the lipopolysaccharide is found to be the most abundant on the surface of a gonococcal cell. It is proven to contribute to the Neisseria gonorrhoeae pathogenesis [39]. Those differences in the OMV structures of the three pathogens are the reason why OMV-based vaccine development and advances will be different but specific to each pathogen.

\section{Updates on the Pre-Clinical and Clinical Study on OMV-Based Vaccine Development}

Chlamydia trachomatis: Bartolini et al. described that C. trachomatis HtrA can be delivered to the OMV compartment, which stimulates antibodies. This is in line with the theory that OMVs carry the majority of the PAMPs found in bacteria. Additional studies are required to assess the level of HtrA protein in OMVs as well as the productive yield of OMV [40]. Currently, one intranasal major outer membrane protein vaccine is being tested pre-clinically as a nano-emulsion [41], but no official results are published assessing the success of this method.

Treponema pallidum: The recent use of M131 as OMV in rabbits to test its immunogenicity showed that the phosphorylcholine surface target of M131 can play a key role for vaccine development [42]. This discovery may serve as a major step towards OMV vaccine development for syphilis, especially after the challenges faced during isolating OMV in Treponema pallidum. More studies are still needed to prove the immunogenicity of M131.

Neisseria gonorrhoeae: Currently, two OMV vaccines exist for Neisseria meningitis $(\mathrm{Nm})$. The impact of the Nm OMV vaccine on Neisseria gonorrhea $(\mathrm{Ng})$ has shown potential cross-reaction [43]. A marked decline in the number of cases of gonorrhea was reported in Cuba following the implementation of the OMV vaccine for meningitis. On the other hand, the number of incidents were rising for the other STDs such as syphilis and genital warts [44]; the same trend was observed in New Zealand [45]. It has been hypothesized that the Nm OMV vaccine could offer protection against gonorrhea. This hypothesis was tested by Petousis-Harris et al. [46], where patients between the ages of 15 and 30 years with a confirmed gonorrhea case were included in the trial. Results showed that patients who received the vaccine had a lower incidence of gonorrhea. Subsequently, another study reported the effectiveness of the vaccine on gonorrhea-associated hospitalization. To understand this cross protection, Davenport et al. [47] shared some pre-clinical evidence that OMV vaccine can reprogram the mucosa area, which allows the cross-protection 
between $\mathrm{Nm}$ and $\mathrm{Ng}$. While the findings are encouraging, rigorous studies will be required in the future to confirm the efficacy of this vaccine.

Although OMVs are potential vaccine candidates, they have some reported limitations that need to be addressed for successful vaccine development. Some of the limitations are (i) the high reactogenicity of pathogen-associated molecular patterns such as LPS, (ii) low expression levels of relevant protective antigens, (iii) strain variation resulting in many subtypes of specific antigens, thus lower coverage, (iv) immuno-dominant antigens that misdirect the immune response, and (v) molecules, which are immunosuppressive or otherwise interfere with a protective immune response. Therefore, genetic engineering of the OMV-producing strain should be applied to overcome those shortcomings by removing, adding, or altering OMV proteins and other components. In addition, preparing a biodegradable and biocompatible polymer-based particulate form of the OMV vaccine can also address this issue [32]. Another approach could be structural modifications to OMV. Kyu-Tae Chang et al. developed a safe and highly effective vaccine delivery system in which OMVs were modified to have properties of intrinsically low endotoxicity sufficient for the delivery of foreign antigens. Their strategy involved mutational inactivation of the MsbB (LpxM) lipid A acyltransferase to generate OMVs of reduced endotoxicity from Escherichia coli (E. coli) O157:H7. The results suggest that by using genetic engineeringbased approaches, the native OMVs could be modified to have both intrinsically low endotoxicity and a foreign epitope tag to establish a platform technology for developing multifunctional vaccine delivery vehicles [48-51].

\section{Particulate Delivery System of Outer Membrane Vesicles (OMVs)}

Although OMV technology is being tested for its use as a vaccine, the structure of OMV is very fragile and vesicle-like, making it unstable. An antigen must keep its structural integrity before uptake by antigen-presenting cells. The destruction of the structure of the antigen before uptake may not trigger immunogenicity. The stability OMVs could be improved by developing a particulate form of vaccine using a biodegradable and biocompatible polymer. The particulate form of a vaccine offers several advantages. Particles can be used as antigen carriers and/or adjuvant in the same preparation [52]. Particulate carriers can also serve as effective antigen delivery systems that can enhance and/or facilitate the uptake of antigens by antigen-presenting cells [53,54]. In addition, the particle can be used as a depot for the controlled release of antigen, thereby increasing the availability of the antigen to the immune cells for a more extended period [55,56]. It can hold more than one antigen and/or adjuvants when needed. Particle formulations possess the ability to modulate the type of immune responses induced when used alone or in combination with other immune-stimulatory compounds [57]. Particulates can protect the integrity of antigens against degradation especially in the harsh acidic conditions of the stomach and enzymatic degradation in the GI tract $[58,59]$. In the case of OMV, the most important challenge is to preserve the integrity of the structure. Thus, a polymeric particulate formulation can protect the fragile structure of OMV.

Recently, polymeric particle formulations have gained great attention in the field of vaccine delivery research due to their potentially advantageous biocompatibility and biodegradability [60]. Several natural and synthetic polymers such as polysaccharides [61], poly(D,L-lactic-coglycolic acid), (PLGA) poly(lactic acid) (PLA) [62], and poly(D,L-lactideco-glycolide) (PLG) [63] have been used to make particles for vaccine delivery. These particles are able to either entrap or adsorb the antigen for delivery to specific cells or allow for sustained antigen release over time because of their slow biodegradation rate [64,65]. The size of OMV ranges from $30 \mathrm{~nm}$ to $70 \mathrm{~nm}$, which may be ideal to prepare nanoparticulate formulation of vaccine delivery system. The unique physicochemical properties of nanoparticles include higher surface-to-volume ratio, small size, ability to encapsulate various drugs, and tunable surface chemistry, which give them many advantages over their bulk counterpart. There are also other biological advantages that include multivalent surface modification with targeting ligands, efficient navigation of the complex in an in vivo 
environment, increased intracellular trafficking, the addition of any charged particles to increase target selectivity, and sustained release of the drug. Together, these advantages make nanoparticles ideal candidates for formulating drugs for the most prevalent and challenging diseases $[66,67]$.

Recently, the integration of synthetic nanoparticles (NPs) and natural cellular materials such as cell membranes or exosomes has led to the creation of various biomimetic nanoparticles that can be applied to OMVs $[68,69]$. OMVs generally have a hollow, vesicular nanostructure composed of phospholipids and lipopolysaccharide (LPS) that contain outer membrane proteins (OMPs) [70]. To improve their stability, G. Wu et al. [71] attempted to reinforce the OMVs structure by depositing the hollow-structured OMVs onto bovine serum albumin (BSA) NPs (BN). BSA protein has a high affinity to complexes with lipid molecules through hydrophobic interaction [71]. Another study reported the development of a novel strategy to engineer protein NPs stabilized by the intermolecular disulfide network [71]. The method employed by G. Wu et al. was green synthetic, easily accessed, and size controlled. Therefore, it was selected to be employed in the development of OMVs nano-vaccine formulation. The goal was to reinforce the OMV structure and uniform their size to prepare membrane-coated BSA nanoparticulate OMVs. The fragile structure of OMVs was observed to be reinforced internally by size-controlled BSA nanoparticles to obtain uniform and stable vaccines through hydrophobic interactions. The result showed that the BSA-OMV nanoparticles (BN-OMVs) were homogenous with a size around $100 \mathrm{~nm}$ and exhibited a core-shell structure. In the in vivo study, the subcutaneous BN-OMVs vaccination had remarkably higher specific antibody titers. This study demonstrated that the structure optimization improved the immune efficacy of OMVs for vaccine development [71].

\section{Conclusions}

STDs present a significant health issue worldwide. Three of the most common STDs are gonorrhea, chlamydia, and syphilis. Currently, only antibiotics are available to treat these diseases therapeutically. However, due to bacterial resistance, the effectiveness of therapeutic antibiotics is decreasing. Therefore, a preventive vaccination approach could be a good alternative to reduce the number of cases caused by STDs. OMV can be a good antigen candidate for vaccine against STDs due their size, immunogenicity, adjuvant potential, and the ability to be taken up by immune cells. The OMV-based vaccination concept is further supported by the pre-clinical and clinical study report. However, the major problem with OMV is its fragile structure. The particulate form of vaccine can address this structure related stability issue. Therefore, the particulate form of OMV can be a good choice for OMV vaccine delivery, which can increase its stability in the system by protecting it from acidic or enzymatic degradation. We also argue that the proposed particle-based OMV vaccine shelf life is expected to be several folds higher than that of conventional vaccines, since it is kept well protected from moisture. More research is needed to investigate the particulate form of OMV vaccines prepared for characterization and in-vitro evaluation.

Author Contributions: Conceptualization, C.C. and M.N.U.; Resources, M.N.U.; Data Curation, S.M.S.; writing - original draft preparation, C.C., M.N.U. and S.M.S.; writing-review and editing, C.C., M.N.U., S.M.S., R.P.G.; Supervision, M.N.U. All authors have read and agreed to the published version of the manuscript.

Funding: This research received no external funding.

Institutional Review Board Statement: Not applicable.

Informed Consent Statement: Not applicable.

Data Availability Statement: Data are available in correspondent journal.

Acknowledgments: The figures in this review were made using biorender.com. 
Conflicts of Interest: The authors declare no conflict of interest.

\section{References}

1. CDC-STD Diseases \& Related Conditions. Available online: https://www.cdc.gov/std/general/default.htm (accessed on 11 June 2021).

2. Kirkcaldy, R.D.; Weston, E.; Segurado, A.C.; Hughes, G. Epidemiology of gonorrhoea: A global perspective. Sex. Health 2019, 16, 401-411. Available online: http:/ / www.publish.csiro.au/?paper=SH19061 (accessed on 12 June 2021). [CrossRef]

3. Table 3. Chlamydia-Reported Cases and Rates of Reported Cases by State/Territory and Region in Alphabetical Order, United States. 2015-2019. Available online: https://www.cdc.gov/std/statistics/2019/tables/3.htm (accessed on 11 June 2021).

4. Schautteet, K.; De Clercq, E.; Vanrompay, D. Chlamydia trachomatis Vaccine Research through the Years. Infect. Dis. Obstet. Gynecol. 2011, 2011, 1-9. Available online: http://www.hindawi.com/journals/idog/2011/963513/ (accessed on 12 June 2021). [CrossRef]

5. Chlamydia Infections Chlamydia Chlamydia Symptoms MedlinePlus. Available online: https://medlineplus.gov/ chlamydiainfections.html (accessed on 11 June 2021).

6. National Overview-Sexually Transmitted Disease Surveillance. 2019. Available online: https://www.cdc.gov/std/statistics/2019 / overview.htm (accessed on 10 September 2021).

7. STD Facts-Syphilis (Detailed). Available online: https://www.cdc.gov/std/syphilis/stdfact-syphilis-detailed.htm (accessed on 11 June 2021).

8. McIntosh, E.D.G. Development of vaccines against the sexually transmitted infections gonorrhoea, syphilis, Chlamydia, herpes simplex virus, human immunodeficiency virus and Zika virus. Ther. Adv. VaccinesImmunother. 2020, 8, 2515135520923887. [CrossRef] [PubMed]

9. Cyr, S.S.; Barbee, L.; Workowski, K.A.; Bachmann, L.H.; Pham, C.; Schlanger, K.; Torrone, E.; Weinstock, H.; Kersh, E.N.; Thorpe, P. Update to CDC's Treatment Guidelines for Gonococcal Infection. MMWR Morb. Mortal. Wkly. Rep. 2020, 69, 1911-1916. Available online: http:/ / www.cdc.gov/mmwr/volumes/69/wr/mm6950a6.htm?s_cid=mm6950a6_w (accessed on 2 July 2021). [CrossRef]

10. Kulp, A.; Kuehn, M.J. Biological Functions and Biogenesis of Secreted Bacterial Outer Membrane Vesicles. Annu. Rev. Microbiol. 2010, 64, 163-184. [CrossRef]

11. Schwechheimer, C.; Kuehn, M.J. Outer-membrane vesicles from Gram-negative bacteria: Biogenesis and functions. Nat. Rev. Microbiol. 2015, 13, 605-619. Available online: http://www.nature.com/articles/nrmicro3525 (accessed on 10 June 2021). [CrossRef] [PubMed]

12. Toyofuku, M.; Nomura, N.; Eberl, L. Types and origins of bacterial membrane vesicles. Nat. Rev. Microbiol. 2019, 17, 13-24. Available online: http:/ / www.nature.com/articles/s41579-018-0112-2 (accessed on 11 June 2021). [CrossRef]

13. Kaparakis-Liaskos, M.; Ferrero, R.L. Immune modulation by bacterial outer membrane vesicles. Nat. Rev. Immunol. 2015, 15, 375-387. [CrossRef] [PubMed]

14. Silhavy, T.J.; Kahne, D.; Walker, S. The Bacterial Cell Envelope. Cold Spring Harb. Perspect. Biol. 2010, 2, a000414. [CrossRef]

15. McBroom, A.J.; Johnson, A.P.; Vemulapalli, S.; Kuehn, M.J. Outer Membrane Vesicle Production by Escherichia coli Is Independent of Membrane Instability. J. Bacteriol. 2006, 188, 5385-5392. [CrossRef] [PubMed]

16. Schwechheimer, C.; Sullivan, C.J.; Kuehn, M.J. Envelope Control of Outer Membrane Vesicle Production in Gram-Negative Bacteria. Biochemistry 2013, 52, 3031-3040. [CrossRef] [PubMed]

17. McBroom, A.J.; Kuehn, M.J. Release of outer membrane vesicles by Gram-negative bacteria is a novel envelope stress response. Mol. Microbiol. 2007, 63, 545-558. [CrossRef]

18. Manning, A.J.; Kuehn, M.J. Contribution of bacterial outer membrane vesicles to innate bacterial defense. BMC Microbiol. 2011, 11, 258. [CrossRef] [PubMed]

19. Maredia, R.; Devineni, N.; Lentz, P.; Dallo, S.F.; Yu, J.; Guentzel, N.; Chambers, J.; Arulanandam, B.; Haskins, W.E. Vesiculation from Pseudomonas aeruginosa under SOS. Sci. World J. 2012, 2012, 1-18. Available online: http://www.hindawi. com/journals/tswj/2012/402919/ (accessed on 14 June 2021). [CrossRef]

20. Jan, A.T. Outer Membrane Vesicles (OMVs) of Gram-Negative Bacteria: A Perspective Update. Front. Microbiol. $2017,8,1053$. Available online: http://journal.frontiersin.org/article/10.3389/fmicb.2017.01053/full (accessed on 14 June 2021). [CrossRef] [PubMed]

21. Schooling, S.R.; Beveridge, T.J. Membrane Vesicles: An Overlooked Component of the Matrices of Biofilms. J. Bacteriol. 2006, 188, 5945-5957. [CrossRef]

22. Schooling, S.R.; Hubley, A.; Beveridge, T.J. Interactions of DNA with Biofilm-Derived Membrane Vesicles. J. Bacteriol. 2009, 191, 4097-4102. [CrossRef]

23. Hashimoto, M.; Matsumoto, T.; Tamura-Nakano, M.; Ozono, M.; Hashiguchi, S.; Suda, Y. Characterization of outer membrane vesicles of Acetobacter pasteurianus NBRC3283. J. Biosci. Bioeng. 2018, 125, 425-431. Available online: https://linkinghub. elsevier.com/retrieve/pii/S1389172317303444 (accessed on 11 June 2021). [CrossRef] [PubMed]

24. Solanki, K.S.; Pal, D.; Kaur, G.; Kumar, P.; Sahoo, M.; Chaudhuri, P. Isolation and Characterization of OMPs and OMVs of Brucella abortus S19 and Brucella abortus S19 per. J. Pure Appl. Microbiol. 2016, 10, 2121-2126. 
25. Bonnington, K.E.; Kuehn, M.J. Protein selection and export via outer membrane vesicles. Biochim. Biophys Acta-Mol. Cell Res. 2014, 1843, 1612-1619. Available online: https://linkinghub.elsevier.com/retrieve/pii/S0167488913004382 (accessed on 11 June 2021). [CrossRef]

26. Bauman, S.J.; Kuehn, M.J. Purification of outer membrane vesicles from Pseudomonas aeruginosa and their activation of an IL-8 response. Microbes Infect. 2006, 8, 2400-2408. Available online: https://linkinghub.elsevier.com/retrieve/pii/S1286457906001808 (accessed on 11 June 2021). [CrossRef]

27. Alves, N.J.; Turner, K.B.; DiVito, K.A.; Daniele, M.A.; Walper, S.A. Affinity purification of bacterial outer membrane vesicles (OMVs) utilizing a His-tag mutant. Res. Microbiol. 2017, 168, 139-146. Available online: https://linkinghub.elsevier.com/ retrieve/pii/S0923250816301176 (accessed on 12 June 2021). [CrossRef]

28. Gnopo, Y.M.D.; Watkins, H.C.; Stevenson, T.C.; Delisa, M.P.; Putnam, D. Designer outer membrane vesicles as immunomodulatory systems-Reprogramming bacteria for vaccine delivery. Adv. Drug Deliv. Rev. 2017, 114, 132-142. [CrossRef] [PubMed]

29. Robbins, P.D.; Morelli, A.E. Regulation of immune responses by extracellular vesicles. Nat. Rev. Immunol. 2014, 14, 195-2018. Available online: http:/ / www.nature.com/articles/nri3622 (accessed on 11 June 2021). [CrossRef] [PubMed]

30. Nøkleby, H.; Aavitsland, P.; O’Hallahan, J.; Feiring, B.; Tilman, S.; Oster, P. Safety review: Two outer membrane vesicle (OMV) vaccines against systemic Neisseria meningitidis serogroup B disease. Vaccine 2007, 25, 3080-3084. Available online: https:/ /linkinghub.elsevier.com/retrieve/pii/S0264410X0700045X (accessed on 11 June 2021). [CrossRef] [PubMed]

31. van der Pol, L.; Stork, M.; van der Ley, P. Outer membrane vesicles as platform vaccine technology. Biotechnol. J. 2015, 10, 1689-1706. [CrossRef]

32. Bachmann, M.F.; Jennings, G.T. Vaccine delivery: A matter of size, geometry, kinetics and molecular patterns. Nat. Rev. Immunol. 2010, 10, 787-796. Available online: http:/ / www.nature.com/articles/nri2868 (accessed on 12 June 2021). [CrossRef]

33. Ellis, T.N.; Kuehn, M.J. Virulence and Immunomodulatory Roles of Bacterial Outer Membrane Vesicles. Microbiol. Mol. Biol. Rev. 2010, 74, 81-94. [CrossRef]

34. Wu, X.; Lei, L.; Gong, S.; Chen, D.; Flores, R.; Zhong, G. The chlamydial periplasmic stress response serine protease cHtrA is secreted into host cell cytosol. BMC Microbiol. 2011, 11, 87. [CrossRef] [PubMed]

35. Elwell, C.; Mirrashidi, K.; Engel, J. Chlamydia cell biology and pathogenesis. Nat. Rev. Microbiol. 2016, 14, 385-400. Available online: http:/ / www.nature.com/articles/nrmicro.2016.30 (accessed on 11 June 2021). [CrossRef] [PubMed]

36. Blanco, D.R.; Champion, C.I.; Dooley, A.; Cox, D.L.; Whitelegge, J.P.; Faull, K.; Lovett, M.A. A Monoclonal Antibody That Conveys In Vitro Killing and Partial Protection in Experimental Syphilis Binds a Phosphorylcholine Surface Epitope of Treponema pallidum. Infect. Immun. 2005, 73, 3083. [CrossRef]

37. Parker, M.L.; Houston, S.; Wetherell, C.; Cameron, C.E.; Boulanger, M.J. The Structure of Treponema pallidum Tp0624 Reveals a Modular Assembly of Divergently Functionalized and Previously Uncharacterized Domains. Stevenson B, editor. PLoS ONE 2016, 11, e0166274. [CrossRef] [PubMed]

38. Gulati, S.; Pennington, M.W.; Czerwinski, A.; Carter, D.; Zheng, B.; Nowak, N.A.; DeOliveira, R.B.; Shaughnessy, J.; Reed, G.W.; Ram, S.; et al. Preclinical Efficacy of a Lipooligosaccharide Peptide Mimic Candidate Gonococcal Vaccine. MBio 2019, 10, e02552-19. [CrossRef]

39. Bartolini, E.; Ianni, E.; Frigimelica, E.; Petracca, R.; Galli, G.; Berlanda Scorza, F.; Norais, N.; Laere, D.; Giguti, F.; Pierleoni, A.; et al. Recombinant outer membrane vesicles carrying Chlamydia muridarum HtrA induce antibodies that neutralize chlamydial infection in vitro. J. Extracell. Vesicles 2013, 2, 20181. [CrossRef] [PubMed]

40. Fattom, A. Development of a Nanoemulsion-Based Vaccine for Chlamydia Infection. Available online: https://grantome.com/ grant/NIH/R43-AI134168-01A1 (accessed on 22 October 2021).

41. Blanco, D.R.; Champion, C.I.; Lovett, M.A. Use of the skin protection assay in experimental syphilis to assess protective immunity against a specific Treponema pallidum surface epitope. FEMS Microbiol. Lett. 2005, 249, 171-175. [CrossRef]

42. Petousis-Harris, H. Impact of meningococcal group B OMV vaccines, beyond their brief. Hum. Vaccin. Immunother. 2018, 14, 1058-1063. [CrossRef] [PubMed]

43. Pérez, O.; Del Campo, J.; Cuello, M.; González, E.; Nuñez, N.; Cabrera, O.; Llanes, R.; Acevedo, R.; Zayas, C.; Balboa, J.; et al. Mucosal approaches in Neisseria Vaccinology. Vaccimonitor 2009, 18, 53-55.

44. Sexually Transmitted Infection (STI) Surveillance (Dashboard) ESR. Available online: https://www.esr.cri.nz/our-services/ consultancy/public-health/sti/ (accessed on 22 October 2021).

45. Paynter, J.; Goodyear-Smith, F.; Morgan, J.; Saxton, P.; Black, S.; Petousis-Harris, H. Effectiveness of a Group B Outer Membrane Vesicle Meningococcal Vaccine in Preventing Hospitalization from Gonorrhea in New Zealand: A Retrospective Cohort Study. Vaccines 2019, 7, 5. [CrossRef]

46. Davenport, V.; Groves, E.; Horton, R.E.; Hobbs, C.G.; Guthrie, T.; Findlow, J.; Borrow, R.; Næss, L.M.; Oster, P.; Heyderman, R.S.; et al. Mucosal Immunity in Healthy Adults after Parenteral Vaccination with Outer-Membrane Vesicles from Neisseria meningitidis Serogroup B. J. Infect. Dis. 2008, 198, 731-740. [CrossRef]

47. Kim, S.-H.; Kim, K.-S.; Lee, S.-R.; Kim, E.; Kim, M.-S.; Lee, E.-Y.; Gho, Y.S.; Kim, J.-W.; Bishop, R.E.; Chang, K.-T. Structural modifications of outer membrane vesicles to refine them as vaccine delivery vehicles. Biochim. Biophys ActaBiomembr. 2009, 1788, 2150-2159. Available online: https://linkinghub.elsevier.com/retrieve/pii/S0005273609002582 (accessed on 12 June 2021). [CrossRef] [PubMed] 
48. Ahmed, A.A.Q.; Qi, F.; Zheng, R.; Xiao, L.; Abdalla, A.M.; Mao, L.; Bakadia, B.M.; Liu, L.; Atta, O.M.; Li, X.; et al. The impact of ExHp-CD (outer membrane vesicles) released from Helicobacter pylori SS1 on macrophage RAW 264.7 cells and their immunogenic potential. Life Sci. 2021, 279, 119644. Available online: https:/ /linkinghub.elsevier.com/retrieve/pii/S00243 20521006305 (accessed on 12 June 2021). [CrossRef]

49. Harrell, J.E.; Kurtz, J.R.; Bauer, D.L.; Prior, J.T.; Gellings, P.S.; Morici, L.A.; McLachlan, J.B. An Outer Membrane Vesicle-Adjuvanted Oral Vaccine Protects Against Lethal, Oral Salmonella Infection. Pathogens 2021, 10, 616. [CrossRef] [PubMed]

50. Gaspar, E.B.; Prudencio, C.R.; De Gaspari, E. Experimental studies using OMV in a new platform of SARS-CoV-2 vaccines. Hum. Vaccines Immunother. 2021, 17, 2965-2968. [CrossRef] [PubMed]

51. Thomasin, C.; Corradin, G.; Men, Y.; Merkle, H.P.; Gander, B. Tetanus toxoid and synthetic malaria antigen containing poly(lactide)/poly(lactide-co-glycolide) microspheres: Importance of polymer degradation and antigen release for immune response. J. Control. Release 1996, 41, 131-145. Available online: https:/ /linkinghub.elsevier.com/retrieve/pii/0168365996013636 (accessed on 12 June 2021). [CrossRef]

52. Mallapragada, S.K.; Narasimhan, B. Immunomodulatory biomaterials. Int. J. Pharm. 2008, 364, 265-271. Available online: http:/ / www.ncbi.nlm.nih.gov/pubmed/18662761 (accessed on 12 June 2021). [CrossRef]

53. Slütter, B.; Soema, P.C.; Ding, Z.; Verheul, R.; Hennink, W.; Jiskoot, W. Conjugation of ovalbumin to trimethyl chitosan improves immunogenicity of the antigen. J. Control. Release 2010, 143, 207-214. Available online: https:/ /inkinghub.elsevier.com/retrieve/ pii/S0168365910000167 (accessed on 12 June 2021). [CrossRef] [PubMed]

54. O'Hagan, D.T. Microparticles and polymers for the mucosal delivery of vaccines. Adv. Drug Deliv. Rev. 1998, 34, 305-320. Available online: http:/ / www.ncbi.nlm.nih.gov/pubmed/10837683 (accessed on 12 June 2021). [CrossRef]

55. Hamdy, S.; Haddadi, A.; Hung, R.W.; Lavasanifar, A. Targeting dendritic cells with nano-particulate PLGA cancer vaccine formulations. Adv. Drug Deliv. Rev. 2011, 63, 943-955. Available online: http://www.ncbi.nlm.nih.gov/pubmed/21679733 (accessed on 12 June 2021). [CrossRef]

56. Mönkäre, J.; Pontier, M.; van Kampen, E.E.; Du, G.; Leone, M.; Romeijn, S.; Nejadnik, M.R.; O’Mahony, C.; Slütter, B.; Jiskoot, W.; et al. Development of PLGA nanoparticle loaded dissolving microneedles and comparison with hollow microneedles in intradermal vaccine delivery. Eur. J. Pharm. Biopharm. 2018, 129, 111-121. Available online: http:/ /www.ncbi.nlm.nih.gov/ pubmed/29803720 (accessed on 12 June 2021). [CrossRef]

57. Bhowmik, T.; D'Souza, B.; Uddin, M.N.; D'Souza, M.J. Oral delivery of microparticles containing plasmid DNA encoding hepatitis-B surface antigen. J. Drug Target. 2012, 20, 364-371. [CrossRef] [PubMed]

58. Bielinska, A.U.; Kukowska-Latallo, J.F.; Baker, J.R. The interaction of plasmid DNA with polyamidoamine dendrimers: Mechanism of complex formation and analysis of alterations induced in nuclease sensitivity and transcriptional activity of the complexed DNA. Biochim. et Biophys. Acta (BBA)-Gene Struct. Expr. 1997, 1353, 180-190. Available online: http://www.ncbi.nlm.nih.gov/ pubmed/9294012 (accessed on 12 June 2021). [CrossRef]

59. Zhao, L.; Seth, A.; Wibowo, N.; Zhao, C.X.; Mitter, N.; Yu, C.; Middelberg, A.P. Nanoparticle vaccines. Vaccine 2014, $32,327-337$. Available online: http:/ / www.ncbi.nlm.nih.gov/pubmed/24295808 (accessed on 12 June 2021). [CrossRef]

60. Janes, K.; Calvo, P.; Alonso, M. Polysaccharide colloidal particles as delivery systems for macromolecules. Adv. Drug Deliv. Rev. 2001, 47, 83-97. Available online: http:/ / www.ncbi.nlm.nih.gov/pubmed/11251247 (accessed on 12 June 2021). [CrossRef]

61. Fredriksen, B.N.; Grip, J. PLGA/PLA micro- and nanoparticle formulations serve as antigen depots and induce elevated humoral responses after immunization of Atlantic salmon (Salmo salar L.). Vaccine 2012, 30, 656-667. Available online: http: / / www.ncbi.nlm.nih.gov / pubmed/22100638 (accessed on 12 June 2021). [CrossRef]

62. Ali, O.A.; Lewin, S.A.; Dranoff, G.; Mooney, D.J. Vaccines Combined with Immune Checkpoint Antibodies Promote Cytotoxic T-cell Activity and Tumor Eradication. Cancer Immunol. Res. 2016, 4, 95-100. Available online: http://www.ncbi.nlm.nih.gov/ pubmed/26669718 (accessed on 12 June 2021). [CrossRef] [PubMed]

63. Zeng, Q.; Li, H.; Jiang, H.; Yu, J.; Wang, Y.; Ke, H.; Gong, T.; Zhang, Z.; Sun, X. Tailoring polymeric hybrid micelles with lymph node targeting ability to improve the potency of cancer vaccines. Biomaterials 2017, 122, 105-113. Available online: http:/ / www.ncbi.nlm.nih.gov/pubmed/28110170 (accessed on 12 June 2021). [CrossRef] [PubMed]

64. O’Hagan, D.T.; Rahman, D.; McGee, J.P.; Jeffery, H.; Davies, M.; Williams, P.; Davis, S.S.; Challacombe, S. Biodegradable microparticles as controlled release antigen delivery systems. Immunology 1991, 73, 239-242. Available online: http:/ / www.ncbi.nlm.nih.gov/ pubmed/2071168 (accessed on 12 June 2021). [PubMed]

65. Xu, X.; Ho, W.; Zhang, X.; Bertrand, N.; Farokhzad, O. Cancer nanomedicine: From targeted delivery to combination therapy. Trends Mol. Med. 2015, 21, 223-232. Available online: http://www.ncbi.nlm.nih.gov/pubmed/25656384 (accessed on 12 June 2021). [CrossRef] [PubMed]

66. Uddin, M.N.; Kouzi, S.A.; Hussain, M.D. Strategies for Developing Oral Vaccines for Human Papillomavirus (HPV) Induced Cancer using Nanoparticle mediated Delivery System. J. Pharm. Pharm. Sci. 2015, 18, 220-234. Available online: https: //journals.library.ualberta.ca/jpps/index.php/JPPS/article/view/22948 (accessed on 12 June 2021). [CrossRef] [PubMed]

67. Balmert, S.; Little, S.R. Biomimetic Delivery with Micro- and Nanoparticles. Adv. Mater. 2012, 24, 3757-3778. Available online: http:/ / www.ncbi.nlm.nih.gov/ pubmed/22528985 (accessed on 12 June 2021). [CrossRef]

68. Gong, Y.-K.; Winnik, F.M. Strategies in biomimetic surface engineering of nanoparticles for biomedical applications. Nanoscale 2012, 4, 360-368. [CrossRef] [PubMed] 
69. Wai, S.N.; Lindmark, B.; Söderblom, T.; Takade, A.; Westermark, M.; Oscarsson, J.; Jass, J.; Richter-Dahlfors, A.; Mizunoe, Y.; Uhlin, B.E. Vesicle-Mediated Export and Assembly of Pore-Forming Oligomers of the Enterobacterial ClyA Cytotoxin. Cell 2003, 115, 25-35. Available online: http:/ /www.ncbi.nlm.nih.gov/pubmed/14532000 (accessed on 12 June 2021). [CrossRef]

70. Wu, G.; Ji, H.; Guo, X.; Li, Y.; Ren, T.; Dong, H.; Liu, J.; Liu, Y.; Shi, X.; He, B. Nanoparticle reinforced bacterial outer-membrane vesicles effectively prevent fatal infection of carbapenem-resistant Klebsiella pneumoniae. Nanomed. Nanotechnol. Biol. Med. 2020, 24, 102148. Available online: http://www.ncbi.nlm.nih.gov/pubmed/31887427 (accessed on 13 June 2021). [CrossRef]

71. Liu, T.; Wang, Y.; Luo, X.; Li, J.; Reed, S.A.; Xiao, H.; Young, T.S.; Schultz, P.G. Enhancing protein stability with extended disulfide bonds. Proc. Natl. Acad. Sci. USA 2016, 113, 5910-5915. [CrossRef] [PubMed] 